\title{
Teaching communication skills: Getting things done (Requesting and responding)
}

Making communication meaningful in English as a foreign language (EFL) context like Nepal is very essential. This lesson focuses on socializing, where students make requests and respond to the requests made.

Proficiency level: (Post-Secondary)

Age Group: 14-18 years

Class time: 2 hours

\section{Objectives}

The activities presented below seek to:

1) Make students able to ask someone to make requests and respond to the requests.

The students are given handouts of some conversations of requests and their responses. They are asked to read those conversations and highlight the requests made and their responses. The students are then divided into pairs or groups and asked to make conversations with their friends, and finally they are asked to perform the role-plays.

Resources: Audio visual clips, handouts.

\section{Procedures}

1. Introduction (10 minutes)
The students are asked to make requests and respond to those requests. A pair can be invited to the front and one of them is asked to make a request. For instance, he or she may ask his friends for (say) a pen, a book or other such things, and the other partner responds to his/her request.

\section{Class discussion (25 minutes)}

The teacher leads the class by giving feedback to their requests and the responses made by their mates. The students are given time to think and prepare dialogues expressing requests along with the responses. The things such as how they initiated, how it went on and how it was ended must be taken into consideration. Later on, they are asked to present (act out) their dialogues in front of the class. The language exponents used by each pair or group is noted down on the board.

\section{Key expressions (25 minutes)}

On the board,the teacher adds some more examples of the language exponents that have been mentioned in the dialogues of the students. e. g. Would you mind opening the door?...., "Could you please switch off the fan ?" ..., "Is it all right if I ...?". The class then prepares the possible list of language exponents for requesting and responding. Likewise, the possible expressions of responding to those requests are also discussed. e. g. "It's okay", "Here you 
are","why not?", "Sure..." and so on. Finally, the responses are categorized in terms of their politeness.

\section{Activity (15 minutes)}

The teacher shows some video clips or makes them listen to some audio clips from the book or from the internet. (www.oxfordlearn.com/login) and the discussion is made on the basis of following questions.

\section{Conversation 1}

- How does Rahul ask his friend to switch off the fan?

- How does his friend respond?

\section{Conversation 2}

- What expression did Harish use to ask for a pen?

- How did Shyam respond?

\section{Conversation 3}

- What exponent does Aditi use to respond the request positively?

- How does Ramu respond to the request politely?

\section{Conversation 4}

- How are the language exponents used by the speakers to respond to the request positively?

\section{(Script Appendix 1)}

The teacher shows some videos from the internet showing the requests and their responses in both ways. The students analyze the conversation shown with their classroom discussion.
1. https:// www.youtube.com/ watch? $\mathrm{v}=944 \mathrm{tb}$ im

2. https://hoprea.wordpress.com/ 2010/11/14/nests-vs-nnets

\section{Activity (20 minutes)}

The students prepare a role play on the basis of discussion and the audio-visual scripts. The role-play is designed to incorporate the discussed key expressions. They also modify their drafts and make changes to create a successful conversation. After the completion of the drafts, they get ready for the role play in the same pair or group. Finally, the students are asked to perform the role plays.

\section{The art of small talk (15 minutes)}

The students are made to watch and listen to the audio-visual clips or read the handouts containing the tips to creating a conversation. The students then read and/ or watch those tips individually and select a few most useful tips. The teacher provides the handouts to the students containing a few tips to create a successful conversation. The teacher then selects a few students and asks them to share the tips that they select and why they select them.

\section{Conclusion (10 minutes)}

The students are given some time for a short oral presentation. They are asked to summarize what they have learned and how they would apply them in their regular conversation. The teacher concludes the lesson by summarizing everyday polite and appropriate language expressions. 


\section{Appendix 1}

\section{Conversation 1}

Rahul: Excuse me, would you mind switching off the fan?

Ashim: Okay, Sure

Rahul : Thank you, Ashim

Ashim : You are welcome.

\section{Conversation 2}

Harish :Shyam, could you please lend me your pen for some time?

Shyam : Okay. Here you are.

Harish : Thanks.

Shyam : It's my pleasure.

\section{Conversation 3}

Prem: Would you like to go swimming with me?

Aditi : Why not. I'm ready.

Prem: What about you Ramu?

Ramu : I'm sorry. I have to help my mother at home.

\section{Conversation 4}

Alan: Would you please bring me a glass of water?

Mohan : Oh, certainly

Alan: Thank you very much.

Mohan : Mention not.

\section{Contributor:}

Rajendra Joshi is an M.Ed. graduate in ELT from Tribhuvan University Nepal. He teaches English in Sainik Awasiya Mahavidyalaya, Teghari-Kailali. He is a life member of NELTA. Email: rajendrajoshi632@gmail. com 